\title{
Pulmonary Hypertension at Admission predicts ICU Mortality in Elderly Critically ill with Severe COVID- 19 Pneumonia: retrospective cohort study
}

\section{Marko Kurnik}

General Hospital Celje: Splosna bolnisnica Celje

Helena Božič

General Hospital Celje: Splosna bolnisnica Celje

\section{Anže Vindišar}

General Hospital Celje: Splosna bolnisnica Celje

\section{Petra Kolar}

General Hospital Celje: Splosna bolnisnica Celje

Matej Podbregar ( $\square$ matej.podbregar@guest.arnes.si )

General Hospital Celje: Splosna bolnisnica Celje https://orcid.org/0000-0001-7750-415X

\section{Research Article}

Keywords: COVID-19, elderly, ICU, mortality, echocardiography, lung ultrasound, pulmonary artery systolic pressure, pulmonary hypertension

Posted Date: February 14th, 2022

DOI: https://doi.org/10.21203/rs.3.rs-1247509/v2

License: (1) This work is licensed under a Creative Commons Attribution 4.0 International License.

Read Full License 
Pulmonary Hypertension at Admission predicts ICU Mortality in Elderly Critically ill with Severe COVID-19 Pneumonia: retrospective cohort study

Kurnik $\mathrm{M}^{1}$, Božič $\mathrm{H}^{1}$, Vindišar $\mathrm{A}^{1}$, Kolar $\mathrm{P}^{1}$, Podbregar $\mathrm{M}^{1, *}$

${ }^{1}$ Department for internal intensive care, General Hospital Celje, Slovenia

*Faculty of Medicine, University of Ljubljana, Slovenia

Short title: Pulmonary Hypertension predicts Mortality in Elderly with Severe COVID-19 Pneumonia

Words count: main text 3300

Correspondence:

Matej Podbregar, MD PhD

Department for internal intensive care, General Hospital Celje, Slovenia

e-mail: matej.podbregar@guest.arnes.si 


\section{Abstract}

Background: Point-of-care ultrasound (POCUS) is a useful diagnostic tool for non-invasive assessment of critically ill patients. Mortality of elderly patients with COVID-19 pneumonia is high and there is still scarcity of definitive predictors. Aim of our study was to assess the prediction value of combined lung and heart POCUS data on mortality of elderly critically ill patients with severe COVID-19 pneumonia.

Methods: This was a retrospective observational study. Data of patients older than 70 years, with severe COVID-19 pneumonia admitted to 25-bed mixed, level 3, intensive care unit (ICU) was analyzed retrospectively. POCUS was performed at admission; our parameters of interest were pulmonary artery systolic pressure (PASP) and presence of diffuse B-line pattern (B-pattern) on lung ultrasound.

Results: Between March 2020 and February 2021, 117 patients aged 70 years or more (average age $77 \pm 5$ years) were included. Average length of ICU stay was $10.7 \pm 8.9$ days. High-flow oxygenation, non-invasive ventilation and invasive mechanical ventilation were at some point used to support $36 / 117$ (31\%), 39/117 (33\%) and 75/117 (64\%) patients respectively. ICU mortality was 50.9\%. ICU stay was shorter in survivors ( $8.8 \pm 8.3$ vs $12.6 \pm 9.3$ days, $p=0.02$ ). PASP was lower in ICU survivors (32.5 \pm 9.8 vs. $40.4 \pm 14.3 \mathrm{mmHg}, p=0.024)$. B-pattern was more often detected in non-survivals $(35 / 59$ (59\%) vs. 19/58 (33\%), p=0.005). PASP and B-pattern at admission were both univariate predictors of mortality. PASP at admission was an independent predictor of ICU (OR 1.0683, 95\%Cl: 1.0108-1.1291, $\mathrm{p}=0.02$ ) and hospital (OR 1.0813, 95\% Cl 1.0125-1.1548, p=0.02) mortality. Ventilator associated pneumonia (VAP) was a strong predictor of ICU and hospital mortality.

Conclusions: PASP at admission is an independent predictor of ICU and hospital mortality of elderly patients with severe COVID-19 pneumonia. During ICU stay development of VAP was a strong predictor of ICU and hospital mortality.

Key words: COVID-19, elderly, ICU, mortality, echocardiography, lung ultrasound, pulmonary artery systolic pressure, pulmonary hypertension 


\section{INTRODUCTION}

Coronavirus disease 2019 (COVID-19) is a multi-system disease caused by the severe acute respiratory syndrome coronavirus 2 (SARS-CoV-2).[1]

In-hospital mortality of older hospitalised COVID-19 patients is high.[2] Frailty is independently associated with higher in-hospital mortality, even though COVID-19 patients with frailty presented earlier to the hospital with less severe symptoms.[2] Factors associated with mortality of elderly people diagnosed with SARS-CoV-2 who lived in institutions or who were hospitalized because of the disease were dementia, diabetes, chronic kidney disease and hypertension.[3]

Echocardiography has become a useful clinical tool both in medical wards and in critical care setting, since it is able to provide information on concomitant clinical conditions (i.e., heart failure) and on current hemodynamic status and heart-lung interactions.[4] In COVID-19 patients, the echocardiographic assessment of the right ventricle (RV) represents a pivotal element in the understanding of current disease status and in monitoring the disease progression. [5]

Most patients hospitalized with COVID-19 had lung ultrasound abnormalities on admission. Pointof-care ultrasound can aid in risk stratification for patients with COVID-19 admitted to general wards and into ICUs.[6]

Aim of current study was to evaluate predictive value on mortality of point-of-care echocardiography and lung ultrasound in elderly critically ill at ICU admission.

\section{METHODS}

\subsection{Setting}

A retrospective study was conducted in mixed 25-bed, level 3, ICU in General and Teaching Hospital Celje, Slovenia during a 6-month period (from October 2020 to March 2021).

\subsection{Patients}

This ICU is specially dedicated for SARS-CoV-2 positive adult ( $\geq 18$ years old) patients. The diagnosis of COVID-19 was made in presence of at least one positive real-time polymerase chain reaction (RTPCR) test for SARS-CoV-2 on respiratory specimen/s (nasopharyngeal swab, sputum, and/or lower respiratory tract specimens).

Pregnant women were not treated in our ICU. Only elderly critically ill patients ( $\geq 70$ years old) were included into final analysis of the study. Patients with previous history of systolic left (severely 
diminished left ventricular ejection fraction, $<30 \%$ ) or right heart failure and/or previously detected pulmonary hypertension (estimated PASP $>35 \mathrm{mmHg}$ ) were not included in the study.

Study was conducted after receiving positive agreement from the Republic of Slovenia National Medical Ethics Committee (No. 0120-168/2021/7, 22 July 2021) and from the Institutional Review Board of General Hospital Celje (No. 17/KS/2021-1, 5 March 2021). Informed consent was omitted due to the retrospective nature of the study.

\subsection{Patient data}

The following patient data was collected from the hospital electronic database BIRPIS21 (SRC Infonet, Kranj, Slovenia): basic demographic data, previous medical history, chronic illnesses (i.e., malignant disease, arterial hypertension, diabetes, heart failure, chronic obstructive pulmonary disease, chronic renal disease).

\subsection{Laboratory}

Majority of laboratory analysis was done in General Laboratory of our institution. In laboratory data we focused on admission data and also on clinically worst laboratory data during the whole ICU stay (i.e., lowest $\mathrm{pH}$, highest $\mathrm{pCO}$, lowest $\mathrm{pO} 2$, highest $d$-dimer, highest troponin $\mathrm{T}$, highest procalcitonin (PCT), highest C-reactive protein (CRP), highest creatinine, highest leucocyte counts, etc.).

\subsection{Echocardiography}

Transthoracic echocardiographic exam with cardiac probe (GE Vivid S60 Ultrasound machine, GE healthcare, USA) was performed by the intensive care specialist at admission. Protocol based admission echocardiography data was recorded in the intensive care information system (Centricity Critical Care, GE healthcare, USA). The examination was recorded for later off-line re-evaluation on the workstation (GE EchoPAC Clinical Workstation Software, GE Healthcare, USA) by the experienced ICU care specialist focusing more on cardiology (MP). The following data was collected: left ventricular ejection fraction (LVEF) by eyeballing, velocity time integral (VTI) in left ventricular outflow tract (LVOT), tricuspid annular plane systolic excursion (TAPSE), minimal and maximal inferior vena cava diameter ( $\mathrm{VCl}$ min, $\mathrm{VCl}$ max, respectively) and pulmonary artery systolic pressure (PASP). PASP was estimated with Bernoulli equation from maximal velocity of tricuspid regurgitation and central venous pressure (CVP).[7] CVP was measured invasively. The definitions of RV dysfunction were based on the American Heart Association Guidelines.[8] 


\subsection{Lung ultrasound}

Lung ultrasound exam with a linear probe (GE Vivid S60 Ultrasound machine, GE Healthcare, USA) was performed by the intensive care specialist at admission. Lungs were examined in 8 standard positions, 4 on each side (upper midclavicular line, lower midclavicular line, upper midaxillary line, lower midaxillary line). Patients were classified into: A-pattern when A lines were detected in all examined positions, mixed pattern, when A and B lines were detected, or diffuse B-lines pattern, when only B-lines or lung consolidations were detected in all examined positions. Presence of pleural effusions and lung consolidations were also recorded.[9] The protocol-based admission lung ultrasound data was collected from the intensive care information system (Centricity Critical Care, GE Healthcare, USA).

\subsection{Treatment}

Treatment data was collected from the intensive care information system (Centricity Critical Care, GE healthcare, USA). All patients were initially treated with methylprednisolone $1 \mathrm{mg} / \mathrm{kg}$ body weight.

For characterising respiratory support, we collected the following data: performance of self proning and proning during mechanical ventilation; frequency and duration of high-flow nasal cannula (HFNC) oxygen therapy, non-invasive ventilation (NIV) and invasive mechanical ventilation (IMV). Duration of HFNC and NIV ventilation was guided by using ROX index.[10] In patients supported with IMV the data of maximal positive end-expiratory pressure (PEEP), maximal peak pressure and maximal tidal volume ever recorded during treatment was recorded. Use of nitric oxide inhalation therapy, norepinephrine, levosimendan, systemic thrombolytic treatment and renal replacement therapy were also recorded.

\subsection{Complications and mortality}

The intensive care and hospital information system were used to collect data on complications (i.e., ventilator associated pneumonia (VAP), catheter-related bloodstream infections, urosepsis, fungal infections), ICU and hospital mortality.

Definitions

VAP was defined as new or changing chest X-ray infiltrate/s occurring more than 48 hours after initiation of invasive mechanical ventilation, plus both of the following: (i) new onset of fever (body temperature $\geq 38^{\circ} \mathrm{C}$ )/hypothermia (body temperature $\leq 35^{\circ} \mathrm{C}$ ) and/or leukocytosis (total peripheral 
white blood cell count $\geq 10,000$ cells $/ \mu \mathrm{L}$ )/leukopenia (total WBC count $\leq 4500$ cells $/ \mu \mathrm{L}$ ) $/>15 \%$ immature neutrophils; (ii) new onset of suctioned respiratory secretions and/or need for acute ventilator support system changes to enhance oxygenation.[11]

Catheter-related bloodstream infection (CRBSI) is defined as the presence of bacteremia originating from an intravenous catheter. Microbiological samples were performed using BacT/ALERT SA (aerobic) and BacT/ALERT SN (anaerobic) bottles incubated in the BacT/Alert 3D blood culture instrument (bioMérieux, Ballerup, Denmark).[12]

Fungal infection was diagnosed as previously described.[13]

\subsection{Primary outcome}

Primary outcomes were mortality at ICU discharge and at hospital discharge. The relationship of echocardiography and lung ultrasound data at admission to the primary outcomes.

\subsection{Secondary outcome}

Secondary outcome was an exploration of the relationship between compilations and ICU mortality.

\subsection{Sample size estimation}

A sample size of 106 patients (53 in each group) was determined for (type I error ( $\alpha$ ) 0.05 and power, type II error ( $\beta$ ) 0.20) for detecting statistically significant differences in PASP between ICU survivors and non-survivors. The difference of $8 \mathrm{mmHg}$ with standard deviation $14 \mathrm{mmHg}$ of PASP between ICU survivors and non-survivors was assumed. MedCalc ver. 12.5 (MedCalc Software Ltd, Ostend, Belgium) was used for sample size estimation.

\subsection{Statistical analysis}

Data were summarized as mean ( \pm standard deviation) for metric variables; absolute and relative frequencies for categorical variables. Tests for normal distributions did not reject the null hypothesis that variables were normally distributed. The Student's $t$-test was used for metric variables and ChiSquare for categorical data. Univariate and multivariate logistic regression modelling, with odd ratios calculations, was used to test the relationship between echocardiography, lung ultrasound data, complications and ICU/hospital mortality. A receiver operating characteristic (ROC) curve analysis was used for testing the predictive ability of PASP for ICU/hospital mortality. The analyses were performed 
using SPSS v.25.0 software package (SPSS Inc., Chicago, IL, USA) and MedCalc ver. 12.5 (MedCalc Software Ltd, Ostend, Belgium). A $p$-value $<0.05$ was considered to define statistical significance.

\section{RESULTS}

Three-hundred-forty-three patients were admitted into ICU during the study period. 208 patients, who were younger than 70 years and 28 patients, who had previously detected pulmonary hypertension/or left heart failure, were excluded. 117 patients were included in the final analysis, 58 ICU survivors and 59 non-survivors. ICU mortality was 50.9\%. The general description of patients, previous history and chronic therapy is presented in Table 1 . There was no difference in average age between survivors and non-survivors ( $76 \pm 5$ years vs. $77 \pm 5$ years, $p=0.2)$. ICU length of stay was shorter in ICU survivors compared to non-survivors ( $8.8 \pm 8.3$ days vs. $12.6 \pm 9.3$ days, $p=0.02$ ).

At admission there was no difference between survivors and non-survivors in vital parameters, however serum lactic values were lower in survivors $(2.1 \pm 1.6 \mathrm{mmol} / \mathrm{L} \mathrm{vs} .3 .8 \pm 4.2 \mathrm{mmol} / \mathrm{l}, \mathrm{p}=0.004)$ (Table 2). Admission $\mathrm{pO}_{2} / \mathrm{FiO}_{2}$ was $80.5 \pm 52.1 \mathrm{mmHg}$, without difference between groups (Table 2).

During ICU stay lower values of $\mathrm{pH}$, higher $\mathrm{pCO}$, lower haemoglobin oxygen saturation (stHbO2), higher leukocyte count, higher creatinine levels, higher C-reactive protein and higher Ddimer were detected in non-survivors compared to survivors (Table 2).

All patients were treated with methylprednisolone (Table 3). Survivors had been shortly noninvasively ventilated (NIV) $(1.5 \pm 0.8$ days vs. $3.2 \pm 2.5$ days, $p=0.01)$ and were less often invasively mechanically ventilated ( $47 \%$ vs $81 \%, p=0.001)$. There was no difference between groups in maximal PEEP or tidal volume recorded during ICU stay; however, recorded max peak pressure on ventilators was higher in non-survivors. Ventilator associated pneumonia (VAP) was more often detected in nonsurvivals ( $49 \%$ vs. $21 \%, p=0.001)$. Comparison of VAP incidence in groups of survivors and nonsurvivors, who were mechanically ventilated, showed no difference ( $44 \%$ vs. $42 \%, p=0.54)$.

An echocardiogram was performed on all patients at admission into ICU (Table 4). There were no differences between groups in LV EF, velocity time integral in left ventricular outflow tract in systole, TAPSE or inferior vena cava diameter during respiration. PASP at admission was lower in survivors compared to non-survivors ( $32.5 \pm 9.8$ vs. $40.4 \pm 14.3 \mathrm{mmHg}, \mathrm{p}=0.024)$.

At ICU admission diffuse B-line pattern and mixed B-line/A-line pattern were most often detected on lung ultrasound examination (Table 4). Diffuse B-line pattern was more often recorded in non-survivors than survivors ( $59 \%$ vs. $33 \%, p=0.005$ ). 
PASP and diffuse B-line pattern were univariate predictors of ICU and hospital mortality (Table 5). PASP was the only independent predictor of ICU mortality (OR $1.0683,95 \% \mathrm{Cl} 1.0108$ to 1.1291 , $\mathrm{p}=0.02$ ) and also hospital mortality (OR $1.0813,95 \% \mathrm{Cl} 1.0125$ to $1.1548, \mathrm{p}=0.02)$. Prediction power of PASP for predicting ICU (Figure 1a) and hospital (Figure 1b) is presented as a receiver operating characteristic curve (ROC curve).

Development of VAP was a strong predictor of ICU mortality (OR $3.6250,95 \% \mathrm{CI} 1.6028$ to 8.1986, $\mathrm{p}=0.002$ ), and also hospital mortality (OR 5.9611, 95\% $\mathrm{Cl} 2.1879$ to $16.2414, \mathrm{p}=0.001$ ).

\section{DISCUSSION}

Our study confirmed that PASP at admission is an independent predictor of ICU and also hospital mortality of elderly patients with severe COVID-19 pneumonia. During ICU stay development of ventilator associated pneumonia was a strong predictor of ICU and hospital mortality.

Right heart failure ("acute cor pulmonale") is a long recognized complication of ARDS in relation to severity of the disease and ventilatory strategies associated with hyper-inflated lungs and permissive hypercapnia.[14, 15] Right heart is also vulnerable in the setting of COVID-19 pneumonia. [16] In our study we have analysed robust and easily obtainable echocardiographic parameters which we measured in all patients at admission to our ICU. We always estimated relative dimension of RV compared to left ventricle (LV) (i.e., smaller, same size, larger); we measured PASP, TAPSE and VCI respiratory dynamics. That is why we have not used more sophisticated parameters of RV function such as RV longitudinal strain obtained by speckle-tracking echocardiography.

In previous study of younger patients (age $62 \pm 13$ years) RV dysfunction was found in $25.5 \%$ unselected patients, $28.9 \%$ patients requiring high-flow oxygen and $41.7 \%$ patients requiring mechanical ventilation.[17] Incidence of LV and RV dysfunction was higher in non-survivors than survivors. In multivariate Cox analysis, high-sensitivity troponin (hs-TNI) elevation, mechanical ventilation and $\mathrm{RV}$ dysfunction were independent predictors of higher mortality.

In small cohort of critically ill (age $64.5 \pm 10$ years) elevated PASP and decreased TAPSE were associated with disease severity and composite endpoints, as well as in-hospital mortality (50\%). Equivalent level of mortality was also observed in the present study.

In 510 non-ICU patients (age 64 \pm 14 years, 66\% male) RV dilation and dysfunction were present in $35 \%$ and $15 \%$, respectively.[18] Pulmonary artery pressure was higher in patients who had RV 
dilatation. There was no difference in TAPSE between patients with or without RV dysfunction or RV dilatation, however TAPSE values were low $(1.9 \pm 0.5 \mathrm{~cm})$. We have also found no difference in TAPSE between survivors and non-survivors, which was low in our both groups (Table 4).

In recent systematic review and meta-analysis TAPSE was not related to mortality in COVID-19 unselected patients.[19] Every $1 \mathrm{~mm}$ decrease in TAPSE was associated with an increase in mortality of approximately $20 \%$.

In study analyzing predictive role of combined cardiac and lung ultrasound in 200 COVID-19 non-ICU patients (age $64.2 \pm 19.2$ years) hemodynamic right-side assessment included measurement of pulmonic flow acceleration time velocity to assess pulmonary vascular resistance, surrogate of pulmonary artery hypertension, and estimated right atrial pressure using the inferior vena cava.[20] Estimation of systolic pulmonary pressure on the basis of tricuspid regurgitation pressure gradient was possible in only $18 \%$, compared to $100 \%$ in our older critically ill. In this study the only echocardiographic parameters associated with adverse outcome in non-adjusted analyses were LVEF, stroke volume index, pulmonic flow acceleration time, and TAPSE. The cutoff values for TAPSE and LVEF were within the lower normal range and thus unlikely to be discriminatory in other populations.[20] However, because of the heightened adrenergic tone in patients with respiratory failure, a "lower normal range" TAPSE or LVEF may reflect early cardiac deterioration. As mentioned previously, in our study TAPSE, which was low in both groups, was not discriminatory.

More advanced echocardiography based on speckle-tracking (i.e., global LV strain, RV longitudinal strain), which can detect subtle function changes [21], were also studied in COVID-19 patients. In 120 non-ICU patients (age $61 \pm 14$ years) LV and RV strain was abnormal in $40 \%$ of patients.[22] Poorer clinical grade and clinical deterioration were mostly associated with worsening RV segmental strain, in a pattern suggestive of acute cor pulmonale. LV and RV strains were strong predictors of mortality and need for intubation in patients with COVID-19 infection.

Pulmonary artery hypertension in the present study was mild to moderate as based on echocardiographic estimates of PASP. A mean PASP of $40 \mathrm{mmHg}$ in the non-survivors would indeed be at the upper limit of normal range, taken into account age, sex, and body weight.[23] On the other hand, TAPSE was decreased but still above the lower limit of normal $(18 \mathrm{~mm})$ in non-survivors.

In a recently published study (age of survivors $(n=69) 62 \pm 13$ years vs age of non-survivors $(n=25) 68 \pm 12$ years), authors hypothesized that myocardial injury and inflammatory changes in COVID19 could be additional causes of ARDS-related acute right heart failure.[24] They therefore assessed the coupling of RV function to the pulmonary circulation in COVID-19 ARDS patients. For this purpose, 
they used bedside transthoracic echocardiography with focus on TAPSE/PASP ratio, previously shown to be a valid surrogate of the gold standard ratio of end-systolic to arterial elastance (Ees/Ea) for the assessment of RV-arterial coupling [25] and an independent predictor of outcome in heart failure and pulmonary arterial hypertension.[26]

TAPSE/PASP is easier to assess and can therefore be part of standard bedside echocardiographic assessments as it does not require off-line analysis of images, specific software and may be a more sensitive assessment of RV-pulmonary artery coupling. High prevalence of RV dilatation and dysfunction in the range of $40-50 \%$ recently reported in patients with COVID-19 underscore the exquisite sensitivity of the RV to this newly appeared viral infection. $[27,28]$. In their study TAPSE/ PASP emerged with equally potent prognostic capability for mortality ( $\mathrm{HR} 0.026$; $95 \% \mathrm{Cl}$ : $0.01-0.579$; $\mathrm{p}=0.019$ ), suggesting a major component of acute cor-pulmonale in COVID-19 ARDS pathophysiology. ROC-determined cut-off TAPSE/PASP value of $0.635 \mathrm{~mm} / \mathrm{mmHg}$. In our study survivors and nonsurvivors had low TAPSE/PASP values compared to upper mentioned cut-off. In our study there was no difference in TAPSE/PASP ratio between groups, this could be related to age and severity of the disease.

Previous study not focused on elderly confirmed that markers of RV (TAPSE $<18.5 \mathrm{~mm}$ ) and LV (LVEF $<64 \%$ ) dysfunction assessed by bedside echo and older age (age $\geq 63$ years ) were independent predictors of mortality in hospitalized moderate to severely ill COVID-19 patients.[29] In this study other variables of RV function, such as fractional area change, were higher, and also RV basal dimension was shorter in survivors. Surprisingly, authors have not detected any difference in PASP between survivors and non-survivors.

The pathophysiology of RV is complex and multifactorial. Direct viral damage, aggravation of systemic inflammatory response and hypoxemia may all contribute to cardiac injury. [30] Furthermore, RV function can be worsened by increased afterload, which is likely to be caused by ARDS, hypoxic pulmonary vasoconstriction, micro-thrombi within the pulmonary vasculature and microvascular injury. More research is needed to elucidate the inflammatory pathways and myocardial pathology responsible for RV dysfunction in patients with COVID-19, and determine whether survivors with pathological RV remodeling remain at risk of adverse outcomes.[18]

The most potent predictor of outcome in ARDS is the $\mathrm{PaO} 2 / \mathrm{FiO} 2$ ratio, which as such is part of the definition of the syndrome.[31] The $\mathrm{PaO} 2 / \mathrm{FiO} 2$ ratio was severely low in our cohort. Most patients in our study have pronounced changes detected on lung ultrasonography (LUS), almost half of included patients and almost $60 \%$ of non-survivors had diffuse B-pattern. B-pattern was univariate predictor of 
ICU and hospital mortality; however, it lost its predictive power in model with pulmonary artery systolic pressure. Use of LUS as a diagnostic tool in critically ill patients for establishing the degree of parenchymal involvement, to assess treatment response, and during follow-up is a common practice that has become a high-quality patient bedside standard of care.[32]

Mortality of our cohort was in range of one other study with the same age rage of included patients.[33] Ventilator associated pneumonia in our patients was a complication, which was associated with increased ICU mortality. Incidence of VAP in our older cohort was higher compered to previously published data (age 64 years, IQR $57-71$ years), 35\% vs. 29\%, respectively; however, the fatality rates were identical.[11] In previous study septic shock at VAP onset (odds ratio [OR] 3.30,95\% $\mathrm{Cl} 1.43-7.61, \mathrm{p}=0.005$ ) and acute respiratory distress syndrome at VAP onset (OR 13.21, 95\% $\mathrm{Cl} 3.05-$ $57.26, p<0.001)$ were strongly associated with mortality.[11]

Recent documents published by the European Association of Cardiovascular Imaging and the American Society of Echocardiography have recommended a FoCUS approach in patients with COVID19.[34, 35] As these guidelines were based on expert opinion rather than outcome data, we aimed to assess whether an even more limited approach is sufficient. We found that an optimal model including only one echocardiographic parameter, PASP, provides information that is potentially valuable for clinical management of elder critically ill with severe COVID-19 pneumonia without previously known pulmonary artery hypertension and with preserved LV function. Further prospective study using easy obtainable parameters confirming our data would be appreciated.

\section{Study Limitations}

Our study has at least two weaknesses. First major limitation is, that this is retrospective cohort study, so we have only been able to collect and re-evaluate every-day ICU clinical practice echocardiography and lung ultrasound data - we see this also as an advantage especially because at admission in our ICU both examinations are included in standard protocol. Probably, more sophisticated and time-consuming methods (i.e., speckle-tracking) would confirm additional and subtler RV dysfunction; however, in critically ill the heart dysfunctions are usually more prominent and that is why they can easily be also detected with robust methods. Second major limitation is relatively low number of included elderly patients. Number of included patients has not allowed us to construct and test more complex regression models. 


\section{CONCLUSIONS}

Current retrospective cohort study, which included elderly critically ill patients with severe COVID-19 pneumonia without previous history of heart failure or elevated PASP, confirmed that PASP at admission predicts the ICU and the hospital mortality. Development of VAP during ICU stay increases mortality of elderly patients with severe COVID-19 pneumonia.

\section{Abbreviations}

ACE: angiotensin-converting enzyme; ALT: alanine transaminase; ARDS: acute respiratory distress syndrome; AST: aspartate aminotransferase; AUC: area under the curve; BMI: Body mass index; BNP: brain natriuretic peptide; B-pattern: diffuse B-line pattern; $\mathrm{Cl}$ : confidence interval; COPD: chronic obstructive pulmonary disease; COVID-19: Coronavirus disease 2019; CRBSI: catheter-related bloodstream infection; CRP: C-reactive protein; CVP: central venous pressure; DAP: diastolic arterial pressure; $\mathrm{EF}$ : ejection fraction; $\mathrm{FiO}_{2}$ : fraction of inspired oxygen; FoCUS: focused cardiac ultrasound study; GGT: gamma-glutamyl transferase; HFNC: high-flow nasal cannula; HR: hazard ratio; hs-Tnl: high sensitivity troponin I; ICU: intensive care unit; IMV: invasive mechanical ventilation; LOS: length of stay; LUS: lung ultrasound; LV: left ventricle; LVOT: left ventricular outflow tract; NIV: non-invasive mechanical ventilation; OR: odds ratio; PASP: pulmonary artery systolic pressure; $\mathrm{pCO}$ : partial pressure of carbon dioxide; PCT: pro-calcitonin; PEEP: positive end-expiratory pressure; pO2: partial pressure of oxygen; POCUS: point-of-care ultrasound; ROC: receiver operating characteristic; rTPA: recombinant tissue plasminogen activator; RT-PCR: real-time polymerase chain reaction; RV: right ventricle; SAP: systolic arterial pressure; SARS-CoV-2: severe acute respiratory syndrome coronavirus 2; StHbO2: oxygen saturation; TAPSE: tricuspid annular plane systolic excursion; VAP: ventilatorassociated pneumonia; VTI: velocity time integral; VCl: vena cava inferior; WBC: white blood cell

\section{Supplementary Information}

Not applicable.

\section{Acknowledgements}

The authors would like to acknowledge the importance of nurses, physiotherapy team and all supportive teams for treatment of our patients. Our thanks to all members of Celje COVID-study group: Parežnik R., Hudournik B., Mežnar M., Valović J., Gulan M., Žgavc B., Gabršček Parežnik L., Triller K., Kolenc A., Kotnik G., Majcen M., Kolenc Dolinar M., Kosi M., Skočir A., Ban B., Štern S., Kalušević D., Mazi P., Berlec M., Jagodič Korošec H., Lalić D., Kus A., Parežnik Slatinek A., Lazić J, Globočnik Šali M., Brecl E., Tumpaj T., Sajovic E., Vajdl T, Tacar P, Markoska M.

\section{Authors' contributions}

H.B. and M.K. were responsible to the acquisition of the data, M.K. and M.P. made substantial contributions to the design of the work, M.K. and M.P. did the analysis and interpretation of data, M.K., H.B., A.V., P.K. and M.P. were responsible for the conception and design of the work, and also for draft and review of the work. M.P. as department head supervised all personnel for employing good clinical practices in day-to-day work, data collection, maintaining patient's privacy and article production. All authors have approved the submitted version and have agreed both to be personally accountable for the author's own contributions and to ensure that questions related to the accuracy or integrity of any part of the work, even ones in which the author was not personally involved, are 
appropriately investigated, resolved, and the resolution documented in the literature. All authors read and approved the final manuscript.

\section{Corresponding author}

Correspondence to Matej Podbregar (matej.podbregar@guest.arnes.si).

\section{Funding}

This research received no specific grant from any funding agency in the public, commercial, or notfor-profit sectors.

Availability of data and materials

The datasets used and/or analyzed during the current study are available from the corresponding author on reasonable request.

\section{Declarations}

\section{Ethics approval and consent to participate}

The study was approved by Republic of Slovenia National Medical Ethics Committee (No. 0120168/2021/7, 22 July 2021) and from the Institutional Review Board of General Hospital Celje (No. 17/KS/2021-1, 5 March 2021). As it was a retrospective analysis, consent to participate does not apply.

\section{Consent for publication}

Not applicable.

\section{Competing interests}

Nothing to declare.

\section{Tables and Figures}

Table 1. General description of patients

Table 2. Clinical condition and laboratory

Table3. Treatment of COVID-19 and compilations

Table 4. Point-of-care ultrasound data

Table 5. Univariate and multivariate logistic regression

Figure 1 a. ROC of Pulmonary Artery Systolic Pressure predicting ICU mortality

Figure 1b. ROC of Pulmonary Artery Systolic Pressure predicting hospital mortality 
Table 1.

\begin{tabular}{|c|c|c|c|c|}
\hline Variable & $\begin{array}{c}\text { All } \\
(n=117)\end{array}$ & $\begin{array}{c}\text { ICU survivors } \\
(n=58)\end{array}$ & $\begin{array}{c}\text { ICU non-survivors } \\
(n=59)\end{array}$ & Statistics (p) \\
\hline Age, years & $77 \pm 5$ & $76 \pm 5$ & $77 \pm 5$ & 0.2 \\
\hline Gender, female/male, $n$ & $31 / 86$ & $22 / 36$ & $9 / 50$ & 0.2 \\
\hline Height, $\mathrm{cm}$ & $173 \pm 7$ & $173 \pm 7$ & $173 \pm 8$ & 0.6 \\
\hline Body weight, kg & $87 \pm 16$ & $91 \pm 18$ & $84 \pm 14$ & 0.023 \\
\hline $\begin{array}{l}\text { Duration of COVID-19 } \\
\text { symptoms, days }\end{array}$ & $7+4$ & $7 \pm 4$ & $7 \pm 4$ & 0.9 \\
\hline ICU LOS, days & $10.7 \pm 9.0$ & $8.8 \pm 8.3$ & $12.6 \pm 9.3$ & 0.02 \\
\hline Hospital LOS, days & $19.5 \pm 10.8$ & $21.3 \pm 10.5$ & $17.9 \pm 10.9$ & 0.09 \\
\hline \multicolumn{5}{|l|}{ Previous history: } \\
\hline $\begin{array}{l}\text { Left ventricular } \\
\text { hypertrophy, } \mathrm{n}\end{array}$ & $21(18)$ & $13(22)$ & $8(14)$ & 0.3 \\
\hline Malignant disease, $\mathrm{n}$ & $23(20)$ & $13(22)$ & $10(17)$ & 0.6 \\
\hline Arterial hypertension, $\mathrm{n}$ & $81(70)$ & $40(70)$ & $41(70)$ & 0.9 \\
\hline Diabetes, $\mathrm{n}$ & $42(36)$ & $21(36)$ & $21(36)$ & 0.9 \\
\hline COPD, n (\%) & $13(11)$ & $6(11)$ & $7(12)$ & 0.5 \\
\hline $\begin{array}{l}\text { Chronic kidney failure, } \\
\mathrm{n}(\%)\end{array}$ & $22(19)$ & $10(2)$ & $12(2)$ & 0.8 \\
\hline \multicolumn{5}{|l|}{ Therapy at home: } \\
\hline Statins, $\mathrm{n}(\%)$ & $37(32)$ & $20(35)$ & $17(29)$ & 0.3 \\
\hline Beta-blocker, n(\%) & $47(40)$ & $24(42)$ & $23(39)$ & 0.4 \\
\hline $\begin{array}{l}\text { Inhalation } \\
\text { corticosteroids, n (\%) }\end{array}$ & $16(14)$ & $8(14)$ & $8(14)$ & 0.6 \\
\hline ACE inhibitors, $n(\%)$ & $48(41)$ & $23(40)$ & $25(42)$ & 0.5 \\
\hline Insulin, $\mathrm{n}(\%)$ & $13(11)$ & $6(11)$ & $7(12)$ & 0.5 \\
\hline Aspirin, n(\%) & $34(29)$ & $18(32)$ & $16(32)$ & 0.4 \\
\hline Diuretics, n(\%) & $25(22)$ & $13(23)$ & $12(20)$ & 0.5 \\
\hline
\end{tabular}

ACE: angiotensin-converting enzyme, COPD: chronic obstructive pulmonary disease, ICU: intensive care unit, LOS: length of stay 
Table 2.

\begin{tabular}{|c|c|c|c|c|}
\hline Variable & $\begin{array}{c}\text { All } \\
(n=117)\end{array}$ & $\begin{array}{c}\text { ICU survivors } \\
(n=58)\end{array}$ & $\begin{array}{c}\text { ICU non-survivors } \\
(n=59)\end{array}$ & Statistics (p) \\
\hline \multicolumn{5}{|l|}{ At admission } \\
\hline Heart rate, bpm & $90 \pm 24$ & $88 \pm 24$ & $92 \pm 24$ & 0.1 \\
\hline Respiratory rate, rpm & $30 \pm 8$ & $28 \pm 6$ & $31 \pm 9$ & 0.3 \\
\hline $\mathrm{SAP}, \mathrm{mmHg}$ & $140 \pm 29$ & $144 \pm 29$ & $136 \pm 28$ & 0.2 \\
\hline $\mathrm{DAP}, \mathrm{mmHg}$ & $68 \pm 15$ & $68 \pm 16$ & $68 \pm 15$ & 0.8 \\
\hline $\mathrm{pO}_{2} / \mathrm{FiO}_{2}(\mathrm{mmHg})$ & $80.5 \pm 52.1$ & $89.2 \pm 59.4$ & $79.9 \pm 48.1$ & 0.3 \\
\hline Lactate, $\mathrm{mmol} / \mathrm{L}$ & $3.0 \pm 3.3$ & $2.1 \pm 1.6$ & $3.8 \pm 4.2$ & 0.004 \\
\hline \multicolumn{5}{|l|}{$\begin{array}{l}\text { Extreme values during } \\
\text { ICU stay }\end{array}$} \\
\hline Highest FiO2, \% & $93 \pm 18$ & $91 \pm 21$ & $95 \pm 14$ & 0.024 \\
\hline Lowest $\mathrm{pH}$ & $7.26 \pm 0.14$ & $7.34 \pm 0.09$ & $7.18 \pm 0.13$ & 0.001 \\
\hline Lowest $\mathrm{pO}_{2}, \mathrm{kPa}$ & $8.02 \pm 3.43$ & $8.29 \pm 1.90$ & $7.74 \pm 4.44$ & 0.4 \\
\hline Highest $\mathrm{pCO}_{2}, \mathrm{kPa}$ & $8.43 \pm 3.48$ & $6.70 \pm 2.43$ & $10.09 \pm 3.54$ & 0.001 \\
\hline Highest $\mathrm{HCO}_{3}, \mathrm{mmol} / \mathrm{L}$ & $28.9 \pm 6.7$ & $28.9 \pm 6.07$ & $30.2 \pm 7.13$ & 0.3 \\
\hline Lowest $\mathrm{StHbO}, \%$ & $84.4 \pm 8.4$ & $86.9 \pm 5.8$ & $78.9 \pm 8.6$ & 0.001 \\
\hline $\begin{array}{l}\text { Highest Creatinine, } \\
\mu \mathrm{mol} / \mathrm{L}\end{array}$ & $221 \pm 195$ & $175 \pm 174$ & $266 \pm 205$ & 0.012 \\
\hline Highest proBNP, pg/ml & $\begin{array}{c}12599 \pm 12160 \\
(n=18)\end{array}$ & $\begin{array}{l}6500 \pm 6363 \\
(n=9)\end{array}$ & $\begin{array}{c}18693 \pm 13790 \\
(n=9)\end{array}$ & 0.028 \\
\hline $\begin{array}{l}\text { Highest Troponin I, } \\
\mathrm{ng} / \mathrm{ml}\end{array}$ & $\begin{array}{c}436 \pm 1518 \\
(n=86)\end{array}$ & $\begin{array}{c}588 \pm 2071 \\
(n=43)\end{array}$ & $\begin{array}{c}284 \pm 571 \\
(n=43)\end{array}$ & 0.4 \\
\hline Highest D-dimer, $\mu \mathrm{g} / \mathrm{L}$ & $\begin{array}{c}9898 \pm 10081 \\
(n=100)\end{array}$ & $\begin{array}{c}6665 \pm 7961 \\
(n=48)\end{array}$ & $\begin{array}{c}12881 \pm 10954 \\
(n=52)\end{array}$ & 0.002 \\
\hline Highest PCT, ng/L & $7.14 \pm 17.2$ & $5.45 \pm 16.40$ & $8.72 \pm 17 \pm 91$ & 0.3 \\
\hline Highest CRP, mg/L & $212 \pm 122$ & $174 \pm 105$ & $248 \pm 127$ & 0.001 \\
\hline $\begin{array}{l}\text { Highest leucocyte count, } \\
10 * 9 / L\end{array}$ & $22.09 \pm 21.33$ & $17.1 \pm 17.0$ & $26.8 \pm 23.9$ & 0.015 \\
\hline $\begin{array}{l}\text { Highest thrombocyte } \\
\text { count, } 10 * 9 / \mathrm{L}\end{array}$ & $271 \pm 169$ & $281 \pm 170$ & $262 \pm 169$ & 0.6 \\
\hline Highest AST, $\mu$ kat/L & $6.33 \pm 19.48$ & $4.43 \pm 18,38$ & $8.13 \pm 20.47$ & 0.3 \\
\hline Highest ALT, $\mu k a t / L$ & $3.27 \pm 8.18$ & $2.34 \pm 6.26$ & $4.14 \pm 9.63$ & 0.2 \\
\hline Highest GGT, $\mu$ kat/L & $3.27 \pm 3.67$ & $2.74 \pm 2.34$ & $4.19 \pm 4.50$ & 0.034 \\
\hline Highest bilirubin, $\mu \mathrm{mol} / \mathrm{L}$ & $11.5 \pm 7.19$ & $12.5 \pm 7.1$ & $13.7 \pm 7.2$ & 0.4 \\
\hline
\end{tabular}

ALT: alanine transaminase, AST: aspartate aminotransferase, BNP: brain natriuretic peptide, CRP: Creactive protein, DAP: diastolic arterial pressure, FiO2: fraction of inspired oxygen, GGT: gammaglutamyl transferase, ICU: intensive care unit, pCO2: partial pressure of carbon dioxide, PCT: procalcitonin, pO2: partial pressure of oxygen, SAP: systolic arterial pressure, StHbO2: oxygen saturation 
Table3.

\begin{tabular}{|c|c|c|c|c|}
\hline Variable & $\begin{array}{c}\text { All } \\
(n=117)\end{array}$ & $\begin{array}{c}\text { ICU survivors } \\
(n=58)\end{array}$ & $\begin{array}{c}\text { ICU non-survivors } \\
(n=59)\end{array}$ & $\begin{array}{l}\text { Statistics } \\
\text { (p) }\end{array}$ \\
\hline \multicolumn{5}{|l|}{ Ventilatory support } \\
\hline Self-proning, n (\%) & $3(3)$ & $1(2)$ & $2(3)$ & 1.0 \\
\hline High-flow, n (\%) & $36(31)$ & $15(26)$ & $21(36)$ & 0.3 \\
\hline Duration of High-flow, days & $2.3 \pm 1.6$ & $2.3 \pm 2.1$ & $2.2 \pm 1.2$ & 0.9 \\
\hline NIV, $n(\%)$ & $39(34)$ & $17(29)$ & $22(37)$ & 0.5 \\
\hline Duration of NIV, days & $2.5 \pm 2.1$ & $1.5 \pm 0.8$ & $3.2 \pm 2.5$ & 0.01 \\
\hline $\mathrm{IMV}, \mathrm{n}(\%)$ & $75(65)$ & $27(47)$ & $48(81)$ & 0.001 \\
\hline Duration of IMV, days & $10.3 \pm 8.7$ & $8.0 \pm 8.5$ & $11.5 \pm 8.6$ & 0.09 \\
\hline Proning during IMV, $\mathrm{n}(\%)$ & $12(10)$ & $2(3)$ & $10(17)$ & 0.04 \\
\hline Maximal PEEP, $\mathrm{cmH}_{2} \mathrm{O}$ & $12 \pm 4$ & $11 \pm 4$ & $12 \pm 3$ & 0.2 \\
\hline Tidal volume, $\mathrm{ml}$ & $536 \pm 110$ & $560 \pm 93$ & $525 \pm 117$ & 0.3 \\
\hline Max Peak pressure, $\mathrm{cmH}_{2} \mathrm{O}$ & $36 \pm 7$ & $32 \pm 7$ & $37 \pm 6$ & 0.01 \\
\hline \multicolumn{5}{|l|}{ Medical and renal support } \\
\hline Methylprednisolone, n (\%) & $116(100)$ & $58(100)$ & $59(100)$ & 1,0 \\
\hline Levosimendan, $\mathrm{n}(\%)$ & $8(7)$ & $5(9)$ & $3(5)$ & 0.4 \\
\hline Nitric oxide inhalation, $\mathrm{n}(\%)$ & $2(2)$ & $2(4)$ & 0 & 0.3 \\
\hline Thrombolysis (rTPA), $n(\%)$ & $3(3)$ & $1(2)$ & $2(4)$ & 0.5 \\
\hline Renal replacement therapy, $\mathrm{n}(\%)$ & $18(16)$ & $4(7)$ & $14(24)$ & 0.012 \\
\hline \multicolumn{5}{|l|}{ Complication rate: } \\
\hline VAP, n (\%) & $41(35)$ & $12(21)$ & 29(49) & 0.001 \\
\hline CRBSI, $\mathrm{n}(\%)$ & $1(1)$ & 0 & $1(2)$ & 0.5 \\
\hline Urosepsis, n (\%) & $24(21)$ & $12(21)$ & $12(10)$ & 0.6 \\
\hline Fungal infection, $n(\%)$ & $35(29)$ & $13(22)$ & $21(36)$ & 0.09 \\
\hline
\end{tabular}

CRBSI: catheter-related bloodstream infection, ICU: intensive care unit, IMV: invasive mechanical ventilation, NIV: non-invasive mechanical ventilation, PEEP: positive end-expiratory pressure, rTPA: recombinant tissue plasminogen activator, VAP: ventilator associated pneumonia 
Table 4.

\begin{tabular}{lcccc}
\hline Variable & $\begin{array}{c}\text { All } \\
(\mathbf{n}=\mathbf{1 1 7})\end{array}$ & $\begin{array}{c}\text { ICU survivors } \\
(\mathbf{n}=\mathbf{5 8})\end{array}$ & $\begin{array}{c}\text { ICU } \text { non-survivors } \\
(\mathbf{n}=\mathbf{5 9})\end{array}$ & $\begin{array}{c}\text { Statistics } \\
(\mathbf{p})\end{array}$ \\
\hline Heart: & & & & \\
LVEF, \% & $51 \pm 15$ & $50 \pm 15$ & $52 \pm 14$ & 0.5 \\
LVOT VTI & $18 \pm 5$ & $18 \pm 5$ & $19 \pm 5$ & 0.2 \\
PASP, mmHg & $36.7 \pm 12.9$ & $32.5 \pm 9.8$ & $40.4 \pm 14.3$ & $\mathbf{0 . 0 2 4}$ \\
TAPSE, cm & $1.95 \pm 0.52$ & $1.93 \pm 0.56$ & $1.97 \pm 0.49$ & 0.7 \\
TAPSE/PASP, cm/mmHg & & & & \\
VCI min. diameter, cm & $1.6 \pm 0.8$ & $1.7 \pm 0.7$ & $1.5 \pm 0.8$ & 0.3 \\
VCI max. diameter, cm & $2.1 \pm 0.5$ & $2.2 \pm 0.5$ & $2.0 \pm 0.6$ & 0.3 \\
\hline & & & & \\
LUNG: & & & & 0.005 \\
Diffuse B-lines pattern, $\mathbf{n}(\%)$ & $54(47)$ & $19(33)$ & $35(59)$ & 0.3 \\
Mixed pattern A- and B-lines, & $40(34)$ & $23(40)$ & $17(29)$ & 0.9 \\
n(\%) & & & & 0.2 \\
Pleural effusion, $\mathbf{n}$ (\%) & $15(13)$ & $8(14)$ & $7(12)$ & \\
Lung consolidations, $\mathbf{n}$ (\%) & $3(3)$ & $3(5)$ & 0 & \\
\hline
\end{tabular}

ICU: intensive care unit, LVEF: left ventricular ejection fraction, LVOT VTI: left ventricular outflow tract velocity time integral, PASP: pulmonary artery systolic pressure, TAPSE: tricuspid annular plane systolic excursion, $\mathrm{VCl}$ : vena cava inferior

Table 5. Univariate and multivariate logistic regression

\begin{tabular}{|c|c|c|c|}
\hline Variable in the model & OR & $95 \% \mathrm{Cl}$ & $\begin{array}{l}\text { Statistics } \\
\text { (p) }\end{array}$ \\
\hline \multicolumn{4}{|c|}{ Univariate predictors of ICU mortality } \\
\hline RV pressure & 1.0680 & 1.0071 to 1.1326 & 0.028 \\
\hline Diffuse B-pattern & 2.9167 & 1.3681 to 6.2182 & 0.006 \\
\hline \multicolumn{4}{|c|}{ Multivariate regression model of ICU mortality } \\
\hline RV pressure & 1.0683 & 1.0108 to 1.1291 & 0.02 \\
\hline Diffuse B-pattern & 2.8125 & 0.8258 to 9.5788 & 0.10 \\
\hline \multicolumn{4}{|c|}{ Univariate predictors of Hospital mortality } \\
\hline RV pressure & 1.0680 & 1.0071 to 1.1326 & 0.028 \\
\hline Diffuse B-pattern & 2.2304 & 1.0000 to 4.9749 & 0.050 \\
\hline \multicolumn{4}{|c|}{ Multivariate regression model - Hospital mortality } \\
\hline RV pressure & 1,0813 & 1,0125 to 1,1548 & 0,0197 \\
\hline Diffuse B-pattern & 2.4281 & 0.6339 to 9.3009 & 0.1955 \\
\hline
\end{tabular}

$\mathrm{Cl}$ : confidence interval, ICU: intensive care unit, OR: odds ratio, RV: right ventricular 
Figure 1a.

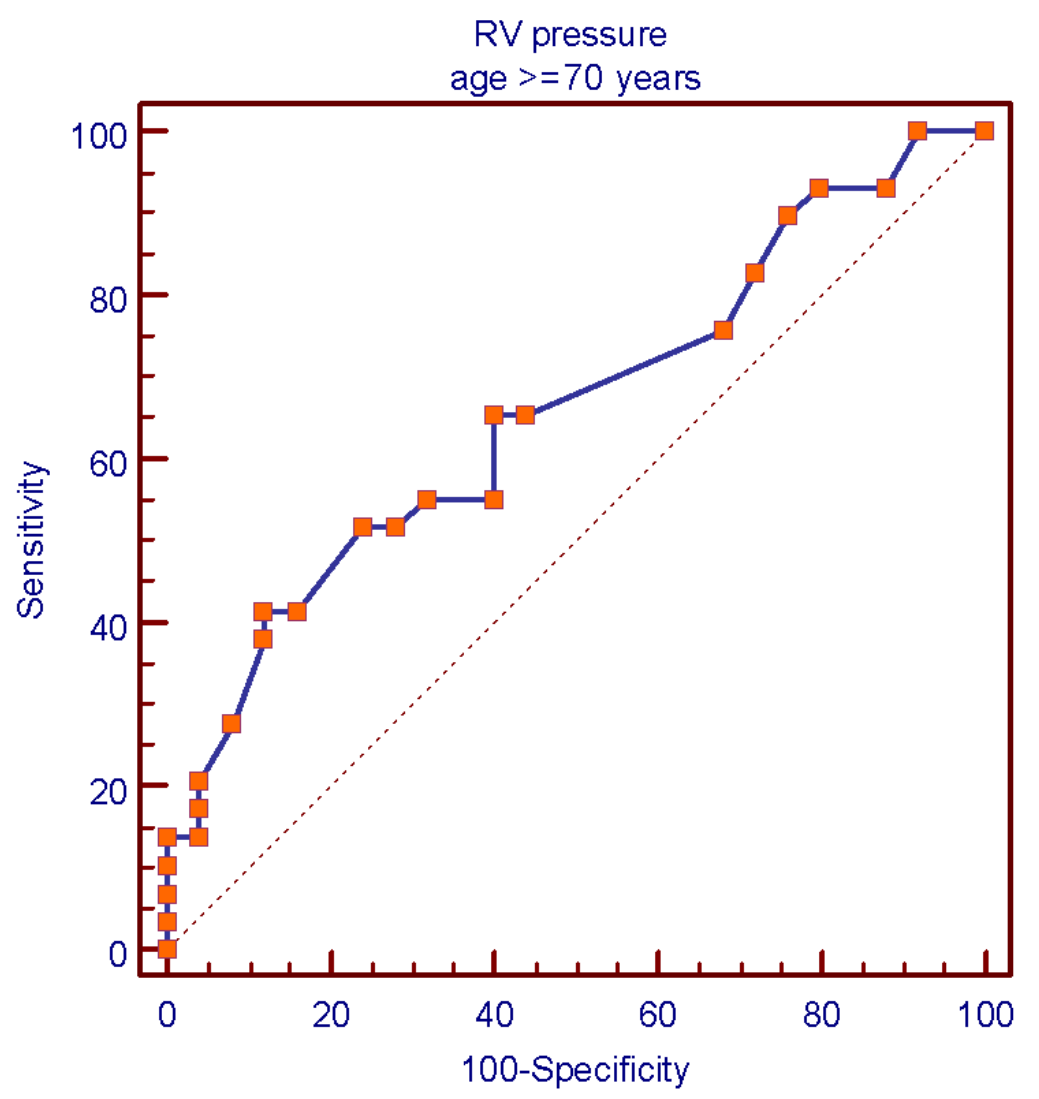

\begin{tabular}{|l|l|}
\hline Area under the ROC curve (AUC) & 0.660000 \\
\hline Standard Error ${ }^{\mathrm{a}}$ & 0.0743 \\
\hline 95\% Confidence interval & \\
\hline z statistic & 0.518386 to 0.783383 \\
\hline Significance level P (Area=0.5) & 0.0312 \\
\hline
\end{tabular}


Figure 2b.

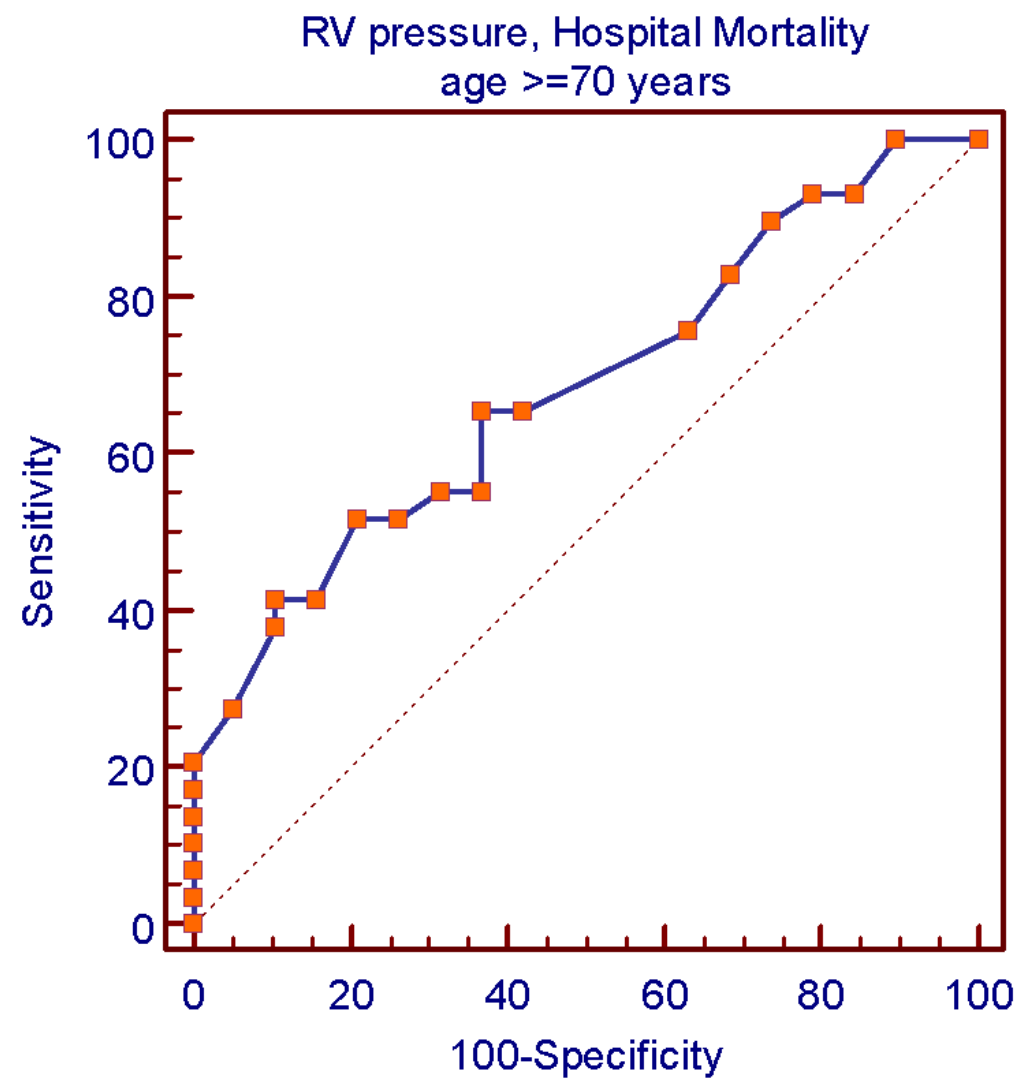

\begin{tabular}{|l|l|}
\hline Area under the ROC curve (AUC) & 0.684211 \\
\hline Standard Error ${ }^{\mathrm{a}}$ & 0.0768 \\
\hline $95 \%$ Confidence interval $^{\mathrm{b}}$ & 0.534058 to 0.810682 \\
\hline z statistic & 2.399 \\
\hline Significance level P (Area=0.5) & 0.0164 \\
\hline
\end{tabular}


Literature

1. Geriatric Medicine Research C, Covid C, Welch C: Age and frailty are independently associated with increased COVID-19 mortality and increased care needs in survivors: results of an international multi-centre study. Age Ageing 2021, 50(3):617-630.

2. Blomaard LC, van der Linden CMJ, van der Bol JM, Jansen SWM, Polinder-Bos HA, Willems HC, Festen J, Barten DG, Borgers AJ, Bos JC et al: Frailty is associated with in-hospital mortality in older hospitalised COVID-19 patients in the Netherlands: the COVID-OLD study. Age Ageing 2021, 50(3):631-640.

3. Alves VP, Casemiro FG, Araujo BG, Lima MAS, Oliveira RS, Fernandes FTS, Gomes AVC, Gregori D: Factors Associated with Mortality among Elderly People in the COVID-19 Pandemic (SARSCoV-2): A Systematic Review and Meta-Analysis. Int J Environ Res Public Health 2021, 18(15).

4. Lazzeri C, Bonizzoli M, Batacchi S, Peris A: Echocardiographic assessment of the right ventricle in COVID -related acute respiratory syndrome. Intern Emerg Med 2021, 16(1):1-5.

5. Paternoster G, Bertini P, Innelli P, Trambaiolo P, Landoni G, Franchi F, Scolletta S, Guarracino F: Right Ventricular Dysfunction in Patients With COVID-19: A Systematic Review and Metaanalysis. J Cardiothorac Vasc Anesth 2021, 35(11):3319-3324.

6. Yasukawa K, Minami T, Boulware DR, Shimada A, Fischer EA: Point-of-Care Lung Ultrasound for COVID-19: Findings and Prognostic Implications From 105 Consecutive Patients. J Intensive Care Med 2021, 36(3):334-342.

7. Kirkpatrick JN, Mitchell C, Taub C, Kort S, Hung J, Swaminathan M: ASE Statement on Protection of Patients and Echocardiography Service Providers During the 2019 Novel Coronavirus Outbreak: Endorsed by the American College of Cardiology. I Am Soc Echocardiogr 2020, 33(6):648-653.

8. Konstam MA, Kiernan MS, Bernstein D, Bozkurt B, Jacob M, Kapur NK, Kociol RD, Lewis EF, Mehra MR, Pagani FD et al: Evaluation and Management of Right-Sided Heart Failure: $A$ Scientific Statement From the American Heart Association. Circulation 2018, 137(20):e578e622.

9. Garcia-Cruz E, Manzur-Sandoval D, Rascon-Sabido R, Gopar-Nieto R, Barajas-Campos RL, Jordan-Rios A, Sierra-Lara Martinez D, Jimenez-Rodriguez GM, Murillo-Ochoa AL, Diaz-Mendez A et al: Critical care ultrasonography during COVID-19 pandemic: The ORACLE protocol. Echocardiography 2020, 37(9):1353-1361.

10. Roca O, Messika J, Caralt B, Garcia-de-Acilu M, Sztrymf B, Ricard JD, Masclans JR: Predicting success of high-flow nasal cannula in pneumonia patients with hypoxemic respiratory failure: The utility of the ROX index. J Crit Care 2016, 35:200-205.

11. Giacobbe DR, Battaglini D, Enrile EM, Dentone C, Vena A, Robba C, Ball L, Bartoletti M, Coloretti I, Di Bella S et al: Incidence and Prognosis of Ventilator-Associated Pneumonia in Critically III Patients with COVID-19: A Multicenter Study. J Clin Med 2021, 10(4).

12. Gahlot R, Nigam C, Kumar V, Yadav G, Anupurba S: Catheter-related bloodstream infections. Int J Crit IIIn Inj Sci 2014, 4(2):162-167.

13. Miller JM, Binnicker MJ, Campbell S, Carroll KC, Chapin KC, Gilligan PH, Gonzalez MD, Jerris RC, Kehl SC, Patel R et al: A Guide to Utilization of the Microbiology Laboratory for Diagnosis of Infectious Diseases: 2018 Update by the Infectious Diseases Society of America and the American Society for Microbiology. Clin Infect Dis 2018, 67(6):e1-e94.

14. Vieillard-Baron A, Price LC, Matthay MA: Acute cor pulmonale in ARDS. Intensive Care Med 2013, 39(10):1836-1838.

15. Repesse $X$, Charron C, Vieillard-Baron A: Acute cor pulmonale in ARDS: rationale for protecting the right ventricle. Chest 2015, 147(1):259-265. 
16. Liu Y, Xie J, Gao P, Tian R, Qian H, Guo F, Yan X, Song Y, Chen W, Fang L et al: Swollen heart in COVID-19 patients who progress to critical illness: a perspective from echo-cardiologists. ESC Heart Fail 2020.

17. Li Y, Li H, Li M, Zhang L, Xie M: The prevalence, risk factors and outcome of cardiac dysfunction in hospitalized patients with COVID-19. Intensive Care Med 2020, 46(11):2096-2098.

18. Kim J, Volodarskiy A, Sultana R, Pollie MP, Yum B, Nambiar L, Tafreshi R, Mitlak HW, RoyChoudhury A, Horn EM et al: Prognostic Utility of Right Ventricular Remodeling Over Conventional Risk Stratification in Patients With COVID-19. J Am Coll Cardiol 2020, 76(17):1965-1977.

19. Martha JW, Pranata R, Wibowo A, Lim MA: Tricuspid annular plane systolic excursion (TAPSE) measured by echocardiography and mortality in COVID-19: A systematic review and metaanalysis. Int $J$ Infect Dis 2021, 105:351-356.

20. Szekely Y, Lichter Y, Hochstadt A, Taieb P, Banai A, Sapir O, Granot Y, Lupu L, Merdler I, Ghantous $E$ et al: The Predictive Role of Combined Cardiac and Lung Ultrasound in Coronavirus Disease 2019. J Am Soc Echocardiogr 2021, 34(6):642-652.

21. Motoki H, Borowski AG, Shrestha K, Hu B, Kusunose K, Troughton RW, Tang WH, Klein AL: Right ventricular global longitudinal strain provides prognostic value incremental to left ventricular ejection fraction in patients with heart failure. J Am Soc Echocardiogr 2014, 27(7):726-732.

22. Li Y, Li H, Zhu S, Xie Y, Wang B, He L, Zhang D, Zhang Y, Yuan H, Wu C et al: Prognostic Value of Right Ventricular Longitudinal Strain in Patients With COVID-19. JACC Cardiovasc Imaging 2020, 13(11):2287-2299.

23. McQuillan BM, Picard MH, Leavitt M, Weyman AE: Clinical correlates and reference intervals for pulmonary artery systolic pressure among echocardiographically normal subjects. Circulation 2001, 104(23):2797-2802.

24. D'Alto M, Marra AM, Severino S, Salzano A, Romeo E, De Rosa R, Stagnaro FM, Pagnano G, Verde $R$, Murino $P$ et al: Right ventricular-arterial uncoupling independently predicts survival in COVID-19 ARDS. Crit Care 2020, 24(1):670.

25. Tello K, Wan J, Dalmer A, Vanderpool R, Ghofrani HA, Naeije R, Roller F, Mohajerani E, Seeger $W$, Herberg $U$ et al: Validation of the Tricuspid Annular Plane Systolic Excursion/Systolic Pulmonary Artery Pressure Ratio for the Assessment of Right Ventricular-Arterial Coupling in Severe Pulmonary Hypertension. Circ Cardiovasc Imaging 2019, 12(9):e009047.

26. Guazzi M: Use of TAPSE/PASP ratio in pulmonary arterial hypertension: An easy shortcut in a congested road. Int J Cardiol 2018, 266:242-244.

27. Szekely Y, Lichter Y, Taieb P, Banai A, Hochstadt A, Merdler I, Gal Oz A, Rothschild E, Baruch G, Peri Y et al: Spectrum of Cardiac Manifestations in COVID-19: A Systematic Echocardiographic Study. Circulation 2020, 142(4):342-353.

28. Mahmoud-Elsayed HM, Moody WE, Bradlow WM, Khan-Kheil AM, Senior J, Hudsmith LE, Steeds RP: Echocardiographic Findings in Patients With COVID-19 Pneumonia. Can J Cardiol 2020, 36(8):1203-1207.

29. Pimentel SLG, Nascimento BR, Franco J, Oliveira KKB, Fraga CL, Macedo FVB, Raso LAM, Avila RE, Santos L, Rocha RTL et al: Bedside echocardiography to predict mortality of COVID-19 patients beyond clinical data: Data from the PROVAR-COVID study. Rev Soc Bras Med Trop 2021, 54:e03822021.

30. Leisman DE, Deutschman CS, Legrand M: Facing COVID-19 in the ICU: vascular dysfunction, thrombosis, and dysregulated inflammation. Intensive Care Med 2020, 46(6):1105-1108.

31. Ferrer M, Sequeira T, Cilloniz C, Dominedo C, Bassi GL, Martin-Loeches I, Torres A: VentilatorAssociated Pneumonia and PaO2/FIO2 Diagnostic Accuracy: Changing the Paradigm? J Clin Med 2019, 8(8).

32. Boero E, Rovida S, Schreiber A, Berchialla P, Charrier L, Cravino MM, Converso M, Gollini P, Puppo M, Gravina A et al: The COVID-19 Worsening Score (COWS)-a predictive bedside tool for critical illness. Echocardiography 2021, 38(2):207-216. 
33. Jung C, Fjolner J, Bruno RR, Wernly B, Artigas A, Bollen Pinto B, Schefold JC, Wolff G, Kelm M, Beil $M$ et al: Differences in mortality in critically ill elderly patients during the second COVID19 surge in Europe. Crit Care 2021, 25(1):344.

34. Skulstad H, Cosyns B, Popescu BA, Galderisi M, Salvo GD, Donal E, Petersen S, Gimelli A, Haugaa $\mathrm{KH}$, Muraru $\mathrm{D}$ et al: COVID-19 pandemic and cardiac imaging: EACVI recommendations on precautions, indications, prioritization, and protection for patients and healthcare personnel. Eur Heart J Cardiovasc Imaging 2020, 21(6):592-598.

35. Kirkpatrick JN, Mitchell C, Taub C, Kort S, Hung J, Swaminathan M: ASE Statement on Protection of Patients and Echocardiography Service Providers During the 2019 Novel Coronavirus Outbreak: Endorsed by the American College of Cardiology. J Am Coll Cardiol 2020, 75(24):3078-3084. 